\title{
A NECESSIDADE INTERPRETATIVA DOS PARADOXOS FUNDAMENTAIS DO DIREITO
}

\author{
Fernando Tonet \\ Doutorando em Direito - Unisinos. \\ fernando.tonet@hotmail.com \\ Recebido em: 17/10/2016 \\ Revisões requeridas em: 12/11/2016 \\ Aceito em: 22/11/2016
}

\section{Resumo}

0 presente artigo analisa os processos de fundamentação das decisões judiciais. Nessa intenção, avalia a conexão da matriz hermenêutica como possibilidade de busca de uma resposta correta aos processos paradoxais, em especial a análise do acórdão da $7^{\mathfrak{a}}$ Câmara Cível do TJRS, na Apelação oㅜ 70005798004, na qual foi discutida a partilha de bens e direitos sucessórios de um genro infiel. Além disso, verificar se a decisão foi correta e se é possível uma resposta correta a partir de uma proposição hermenêutica. 0 método de abordagem será o hermenêutico filosófico, pois possibilita observar o fenômeno do constitucionalismo complexo na pós-modernidade, o que constitui a essência do pensamento constitucional pós-moderno, ensejando uma interpretação acerca da condição de resposta das teorias clássicas em relação à complexidade das sociedades contemporâneas.

\section{Palavras-chave}

Decisão. Hermenêutica. Paradoxo.

\section{THE INTERPRETATIVE NECESSITY OF THE FUNDAMENTAL PARADOXES OF LAW}

\section{Abstract}

This article analyzes the reasoning processes of judicial decisions. With this intention, it evaluates the hermeneutic matrix's connection as a possibility to search for a correct answer to the paradoxical processes, in particular the analysis of the decision made by the $7^{\text {a }}$ Câmara Cível do TJRS, in Appeal No. 70005798004, which discussed the property division and and inheritance rights of an unfaithful son in law. Also check whether the decision was correct and if it is possible a correct answer from a hermeneutic proposition. The approach method is the philosophical hermeneutic, as it allows the observation of the phenomenon of complex constitutionalism in postmodernity, what constitutes the essence of postmodern constitutional thought, giving rise for an interpretation on the response status of the classical theories in relation to the complexity of contemporary societies.

\section{Keywords}

Decision. Hermeneutics. Paradox. 


\section{Sumário}

1 Considerações iniciais. 2 A necessidade interpretativa dos paradoxos fundamentais do Direito. 2.1 A indignidade e os benefícios da torpeza. 2.2 Breve análise reflexiva da congruência panprocessual na esfera criminal. 3 Uma análise hermenêutica da abertura interpretativa da Apelação Cível número 70005798004/2003 - 7․ Câmara Cível - TJRS. 3.1 Apelação Cível número 70005798004/2003 - 7ํ. Câmara Cível - TJRS e sua resposta correta. 3.2 Etapas da interpretação para uma resposta correta. 4 Considerações Finais. 5 Referências. 


\section{CONSIDERAÇÕES INICIAIS}

O presente artigo trabalha em um viés hermenêutico um dos principais problemas da justiça, a decisão judicial e seu embasamento teórico. Para tanto, utiliza-se de uma perspectiva epistemológica que busca constranger positivamente os tribunais e julgadores a (re)fazerem suas decisóes de forma correta, preservando a integridade do direito e a evoluçáo jurisdicional. Nesse ideário, optou-se por estabelecer como marco teórico e metodológico a teoria hermenêutica filosófica, pois oferece ferramentas necessárias para o desenvolvimento complexo das decisóes judiciais dentro de um sistema jurídico coerente e reflexivo.

O método de abordagem hermenêutico filosófico possibilita a elaboração das decisôes judiciais mediante a utilização correta das normas jurídicas (regras e princípios) nos casos difíceis ou paradoxais, pois muitas vezes, em casos de lacunas jurídicas ou decisóes legalmente injustas, deve-se buscar uma estrutura principiológica que possibilite a derrotabilidade das regras aplicáveis, para se manter a estrutura do sistema jurídico, inclusive entre áreas, como é o caso analisado, em que a congruência panprocessual deve ser mantida.

Dessa forma, trilhamos, por meio da hermenêutica, caminhos possíveis para uma decisão judicial correta, ou a mais correta para o caso concreto, em que se possa caminhar como em um romance literário na construção de uma fundamentação judicial que possibilite a evolução do sistema jurídico com integridade e seriedade.

O trabalho analisa a crise hermenêutica vivida pelos tribunais, na aplicação das sentenças judiciais e suas conseqüências no mundo da vida. Bem como a aplicação da congruência panprocessual na busca por uma estrutura jurídica que não se contradissesse em cada decisão, para que o sistema possa se manter íntegro e harmônico sob um viés constitucional. Ainda, analisando a Apelação Cível número 70005798004/2003 - 7a Câmara Cível - do Tribunal de Justiça do Estado do Rio Grande do Sul, buscar-se-á constranger epistemologicamente os votos dos Desembargadores. 


\section{A NECESSIDADE INTERPRETATIVA DOS PARADOXOS FUNDAMENTAIS DO DIREITO}

No complexo conjunto que forma o sistema jurídico, muitos elementos fundamentais permaneceram obscuros, traduzimos essas emergências interpretativas a partir de casos difíceis, ou, como preferimos, paradoxos do Direito. Os novos processos civilizacionais, criados pelos múltiplos contextos sociais, necessitam de perspectivas epistemológicas que possibilitem uma real análise de seus quadros jurídicos, dentro das dobraduras reflexivas oriundas das saliências existentes na atual crise de fundamentação teórica hermenêutica.

Diante da complexidade contemporânea, a lei não pode prever todas as hipóteses de aplicação para todos os casos existentes, devido a uma porosidade normativa que resulta na situaçáo de nem todos os casos poderem ser contemplados, contexto que força cada vez mais a utilização de princípios para fechar tanto interpretaçôes quanto respostas coerentes com o ordenamento jurídico.

Assim, uma interpretação íntegra deve ser pautada pela busca de um princípio de fundamento moralmente político e jurídico. Esse princípio deve ter capacidade de afastar a regra geral, trazendo à tona a derrotabilidade da norma, dentro de uma perspectiva de congruência panprocessual. A referida derrotabilidade normativa pode ser articulada na forma de uma interpretação literária, extremamente próxima da jurídica, como um romance em cadeia demonstrando que essa resposta é reflexo da integridade e da coerência do direito.

Tanto no processo penal quanto no processo civil, as aplicaçóes hermenêuticas têm se apresentado de forma equivocada, criando uma verdadeira crise no sistema jurídico. Em suma, os magistrados primeiramente julgam, para depois fundamentarem suas decisóes. Toda busca íntegra por uma resposta adequada ao ordenamento constitucional passa por uma séria análise do sistema jurídico, para a criação de uma decisão, assim, é necessário fundamentar as teses para depois decidir, e não ao contrário.

\subsection{A indignidade e os benefícios da torpeza}

O presente caso é uma ação julgada pela $7^{\text {a }}$ câmara cível do Tribunal de Justiça do Estado do Rio Grande do Sul. Trata-se de uma análise jurídica ao direito de meação no divórcio no qual se verifica indignidade por parte do autor de um delito 
punido criminalmente. O processo teve início em 1997, quando regia o código civil de 1916, os fatos demonstraram que a apelante foi casada com o apelado, e que aquele assassinou seu pai por motivo torpe. Após a condenaçáo criminal, a mesma buscou divórcio, no qual o apelado requereu seu direito de meação.

Ocorre que todos os bens da apelante foram provenientes da herança deixada por seu pai. Assim, alega não ser justo que o seu ex-marido possa ter direitos de meaçáo, beneficiando-se dos seus atos criminais. O código civil de 1996, entretanto, em seu artigo 1.595, trata apenas como infiéis no recebimento de herança, os herdeiros e não os cônjuges dos herdeiros. Tal lacuna verifica-se também no código civil de 2002 em seu artigo 1.814, que também não previu tal exclusão por infidelidade.

O relator do caso demonstrou-se um positivista lógico, aplicando exclusivamente a norma, sustentando que a exclusão legislativa corresponde exclusivamente ao herdeiro e não ao cônjuge-meeiro, pois embora o apelado seja autor do homicídio, não é herdeiro da vítima, não podendo se admitir analogicamente uma interpretação extensiva que restringisse o direito da meação. Votou pelo desprovimento do apelo.

A presidente da câmara criminal concorda com o relator que tal fato não foi vislumbrado pelo código civil de 1916, porém, no momento em que o legislador criou a figura do herdeiro infiel, mostrou o elevado teor moral da norma, criando uma repulsa mesmo que não positivada de benefício do infiel. A lei não permite que o herdeiro se beneficie do crime, pois bem, o apelado não é herdeiro, mas é ex-marido da herdeira e os bens provenientes da meação correspondem à herança recebida pela apelante. Utilizando seu "senso de justiça" a presidente da câmara votou pelo provimento da apelação.

Embora a presidente tenha se utilizado de um fundamento básico de moralidade legal, acabou fundamentando conforme sua consciência, sem um embasamento epistemológico avançado ou uma derrotabilidade da norma, conceito positivado no artigo 1.595 do código civil de 1916.

O último desembargador a analisar o caso, se pautou pelo artigo $4^{\circ}$ da Lei de Introdução ao Código Civil, segundo o qual o juiz decidirá em casos omissos de acordo com a analogia, costumes e princípios do Direito, porém, não apresenta analogia, costumes ou princípios para o caso, utilizando o senso comum como fundamentação final. 
Embora, tenha se chegado a uma decisão possivelmente justa, essa não foi fundamentada pelos julgadores, que poderiam ter explorado o ordenamento jurídico e decidido de forma coerente e íntegra, pautando-se por elementos materiais que estão no próprio sistema jurídico e não em suas consciências.

\subsection{Breve Análise Reflexiva da Congruência Panprocessual na Esfera Criminal}

Estuda-se no direito moderno o instituto da congruência panprocessual, ou seja, uma decisão condenatória na esfera criminal não poderia gerar benefícios na esfera civil, pois estaria rompendo com a adequação, integridade e harmonia entre os institutos jurídicos. Assim, a sentença condenatória, deveria ter - por meio dos efeitos da condenação elencados no código penal, artigo 91, II, b - limitado os direitos em relação à meação advinda da área cível.

Segundo Zaffaroni e Pierangeli (2015, p. 765), a sentença criminal é a manifestação da vontade estatal, extraída da própria legalidade, assim, seus efeitos são caudatários do ordenamento constitucional, garantidos pelo princípio da legalidade - a lei criminal é expressa quando sustenta que o produto do crime ou qualquer outro proveito auferido pelo agente na prática do ato criminoso deve ser perdido. Assim, não poderia o juízo cível conceder benefícios da meação ao criminoso, pois estaria rompendo com a integridade jurídica.

Os efeitos da condenação não são novos no ordenamento jurídico, nasceram na década de 40 do século passado, juntamente com o código penal. Roberto Lyra (1942, p. 462), sustentava que qualquer bem que importe proveito, que haja sido auferido com o crime deve ser confiscado. Nos mais distintos ordenamentos do mundo ocidental ${ }^{1}$, os efeitos da condenação proíbem

Tal posicionamento é tão cristalino nas legislaçôes internacionais, que podemos mencionar: Código Penal Italiano, em seu artigo 185, onde todo crime obriga a restituiçâo das coisas e perda dos benefícios auferidos; Código Penal Uruguaio, em seu artigo 104, todo delito que se traduza, direta ou indiretamente, por mal patrimonial, acarreta, como conseqüência, responsabilidade civil; Código Penal Argentino, em seu artigo $29,2^{\circ}$, a sentença penal condenatória poderá ordenar a restituição da coisa obtida pelo delito; Código Penal Peruano, em seu artigo 65, o Ministério Público promoverá a restituição da coisa; Código Penal Cubano, em seu artigo 110, todo fato sancionável acarreta a responsabilidade civil, por responsabilidade civil compreende: a restituição in integrum; Código Penal Dinamarquês, em seu artigo 77, diz que o criminoso não pode auferir bens com seu ato criminoso em prol de uma segurança pública. Ver. LYRA, Roberto. Comentários ao Código Penal. Vol. II. Rio de Janeiro: Revista Forense, 1942, p. 450 a 459. 
o agente criminoso de auferir lucro com seus atos. Nesse sentido, utilizando-se de pressupostos básicos do ordenamento jurídico, poderia ser vencida a regra de que apenas o herdeiro é infiel, pois para lei criminal, infiel é todo criminoso punido pela força estatal.

Ao tratar das causas legais de deserdação, Pontes de Miranda (1973, p. 267), sustenta que não se necessita nem de uma condenação criminal para haver a deserdação, ou seja, ao dizer isso, pode-se entender que havendo condenação criminal, independentemente de quem seja o autor, este não pode auferir valores - essa também é a posição de Beviláqua (1975, p. 780). Mesmo que, para o código penal, o autor do crime seja uma figura una, pode-se questionar se no direito civil entre a figura do herdeiro e descendente, não pode haver uma figura intermediária. Esse intermediário, mesmo não elencado pela legislação civil, pode ser o cônjuge infiel ao direito sucessório, pois suas ligaçóes pessoais com o herdeiro ou descendente, incluiriam nos benefícios obtidos pela herança.

Toda resposta ao presente caso pressupóe um pedestal de pressuposiçóes do Direito. Em uma análise teórico-reflexiva, as decisões do direito, vem de seus próprios pressupostos, assim, em última análise, todas as fontes jurídicas estão no próprio sistema do direito. Dessa forma, a validade do fundamento construído passa por uma mútua circularidade, em que "a decisão exige a regra como seu pressuposto na mesma medida que esta exige aquela" (CLAM, 2006, p. 120), os paradoxos e limitações comunicativas surgem com a própria positivação do sistema jurídico, e para que se possa oferecer uma garantia jurídica na decisão, o intérprete necessita entrar na rede de circularidade reflexiva do intérprete.

Todo paradoxo nasce da perplexidade da impossibilidade de se manter apegado à norma legal vaga, assim, a busca por uma teoria que trabalhe as nodosidades de forma a buscar um clareamento do objeto jurídico é o ponto crucial no presente caso. Os juristas necessitam de sensibilidade poética para resolver casos complexos, Dworkin (2014) compreendeu isso ao analisar o processo como uma construção literária. Analisando Eumênides, Ésquilo (2003) sai da vingança privada para o conceito de justiça, na Antígona, Sófocles (1950), busca demonstrar a justiça, na recusa de uma injustiça, a interpretação surge nesses casos como uma construção literária em sequência lógica. 


\section{UMA ANÁLISE HERMENÊUTICA DA ABERTURA INTERPRETATIVA DA APELAÇÃO CÍVEL NÚMERO 70005798004/2003 - 7ª CÂMARA CíVEL - TJRS}

A hermenêutica possibilitou novos horizontes ao sistema jurídico, pois trouxe ferramentas ao jurista para que possa trabalhar seus casos com a norma e além da norma, mantendo a integridade normativa. Em Dworkin (2014), o direito é criado pelas práticas sociais e decisóes judiciais, assim o intérprete analisa os fatos sociais na melhor luz para sua aplicação. Importante frisar que não existe uma resposta de antemão, pronta para todos os casos, ela deve ser construída, fundamentada para se chegar a uma boa resposta.

Analisando-se a Apelação Cível número 70005798004/2003 - 7a Câmara Cível - TJRS, verifica-se que a regra é porosa, pois necessita da linguagem, da pragmática para buscar uma aplicação - já os princípios justificam essa regra, assim, os princípios utilizados nos casos difíceis ajudam no fechamento interpretativo.

Quando analisamos em Dworkin (2014, p. 37), encontramos o caso Riggs contra Palmer, no qual um Tribunal de Nova York decidiu se um herdeiro nomeado no testamento por seu avô poderia herdar mesmo tendo assassinado o mesmo. O Tribunal entendeu que a ninguém será permitido lucrar com sua própria torpeza. O Tribunal gaúcho enfrentou caso parecido com o referido, pelo fato de que as leis existentes não eram claras ou eram inexistentes no caso em concreto. Os juízes não chegaram à unanimidade no caso, uma vez que, no TJRS, um desembargador fundamentou sua decisão em uma lacuna jurídica e os outros dois em sua consciência, utilizando a lógica de que todas as leis devem ter uma limitação.

$\mathrm{Na}$ análise do pensamento de Carneiro (2011, p. 267), o julgar de modo não discricionário não se esgota na mera fundamentação das decisóes neste ou naquele princípio - o que, segundo o autor, é muito comum no Brasil - o que se apresenta aos julgadores que se utilizam do princípio que melhor lhes convêm, fundamentando após já terem decidido o caso. Segundo o autor, na linha dworkiana, toda discricionariedade deve se basear numa tese de integridade.

A integridade não é um espaço em que o juiz possa usar sua discricionariedade havendo lacunas, mas uma construção na qual se utiliza o princípio mais adequado para determinado caso. Esse princípio passa por uma aceitabilidade de adequação da sociedade política, dentro de uma autoridade moral. Trata-se de uma 
construção social, não pode ser vista individualmente, por isso, mesmo que a decisão judicial seja feita por um julgador, ela é paradoxal, pois não pode exclusivamente demonstrar o pensamento daquele que julga, mas sim, a integridade de todo o sistema jurídico, ou seja, deve ser entendida pela visão do outro.

Para manter a integridade do sistema jurídico é necessário um alto rigor epistemológico. Segundo Heidegger (2008, p. 47), apenas com o rigor pode-se conquistar a verdade, assim, quando os juízes se utilizam de uma fundamentação séria, rigorosa, observando texto e norma, eles podem chegar a uma resposta correta, ou a mais correta para o caso.

Interessante o posicionamento de Streck (2015), no que concerne à manutençáo da integridade do sistema jurídico, quando trabalha a diferença entre decisão e escolha. Para o autor, a decisão jurídica não pode ser um simples ato de vontade do julgador, diante de várias possibilidades de julgamento, ou a que lhe parece mais adequada ao caso, ao contrário, decidir não é sinônimo de escolher. A decisão não nasce da discricionariedade, toda decisão tem compromisso com a integridade judicial, ou seja, ela parte da história do próprio direito, já a escolha (muito utilizada nos tribunais brasileiros), utiliza-se apenas da vontade tacanha do julgador, que por pensar estar fazendo Direito, julga a seu bel-prazer, sem fidelidade alguma com a ciência jurídica.

Em suas colunas no Conjur, Lenio Streck, trabalha decisões dos tribunais superiores, porém, para a grande maioria dos juristas, a realidade é a aplicação judicial de primeiro grau, imperando a soberania irrestrita do juiz e dos representantes do Ministério Público, que se utilizam do direito da melhor forma que lhes convêm. Observe-se, nesse sentido:

I) Denúncia oferecida pelo Ministério Público do Estado do Mato Grosso, na comarca de Ribeirão Cascalheira - processo criminal n. ${ }^{\circ} 29 / 2011$, em que $o$ denunciado estaria portando uma luneta, caracterizando um acessório de uso restrito no artigo 16, da Lei 10.826/2003. Ocorre que tal luneta é vendida livremente em todas as lojas de caça e pesca, bem como pela internet, assim, nos perguntamos qual é o perigo em concreto que uma luneta possa criar em sociedade? Quais são as diferenças entre ela, um binóculo ou um telescópio? 
Aliás, perante o Ministério Público, o proprietário de um telescópio tem sérias possibilidades de se tornar um terrorista, pois se o proprietário de luneta é criminoso, o que se dirá dos outros. Infelizmente, o réu pobre, proprietário de refeitório em um colégio, ficou preso por mais de 10 horas até que o juiz lhe concede liberdade provisória. A famosa frase castelhanha que "La ley es como la serpiente; solo pica a los descalzos", deixa de ser uma parábola e se torna uma máxima.

Caso semelhante, foi narrado por Streck (2016), em sua coluna semanal, em que um jovem teve de recorrer até o STF para poder se livrar de uma condenação criminal, por utilizar um pingente em formato de munição calibre $0,40 \mathrm{~S} \& \mathrm{~W}$. Qual o objetivo concreto do Ministério Público, como fiscal da lei em punir portadores de pingentes e lunetas?

II) Denúncia oferecida pelo Ministério Público do Estado do Rio Grande do Sul, na comarca de Guaporé - processo criminal n. ${ }^{\circ}$ 053/2.08.0002423-1, em que o denunciado teria se apropriado de um cobertor, um chinelo e três pares de meia. Cujo valor feito pericialmente, por uma avaliaçáo indireta estaria em torno de 300 reais.

Especificamente, sobre a apropriação, não existiu em momento algum prova da materialidade do fato, da materialidade dos bens apropriados, bem como a avaliação foi feita indiretamente, ou seja, o perito judicial vai até sites de vendas da internet e retira os preços que pensa ser mais justos. No final, o representante do Ministério Público, pediu absolvição, por não haver provas da materialidade delitiva. Pois bem, nos questionamos quais os motivos que levaram o MP a oferecer a denúncia se não havia materialidade? Isso mostra que o Ministério Público denuncia e denuncia mal, pois não tem capacidade epistemológica de analisar a prova antes de tomar qualquer medida.

III) Denúncia oferecida pelo Ministério Público do Estado do Rio Grande do Sul, na comarca de Marau - processo criminal n. ${ }^{\circ}$ 109/2.15.0000447-6, em que o denunciado teria cometido estupro, estupro qualificado e estupro de vulnerável, condenando-o a 11 anos de prisão em regime fechado. Ocorre que o réu não cometeu o crime de estupro, mas contravenção penal estabelecida no artigo 61, do Decreto-Lei no $3.688 / 41$, pois apenas importunou as três vítimas em via pública 
em horários diurnos - importante frisar que o réu passou mais de 11 meses em prisão preventiva, antes que o Tribunal de Justiça do Rio Grande do $\mathrm{Sul}^{2}$ pudesse reverter a decisão por unanimidade.

IV) Processo de execução criminal na comarca de Passo Fundo - processo de execução criminal n. ${ }^{\circ} 118239-0^{3}$, em que os juízes responsáveis pela VEC criaram a Portaria n. ${ }^{\circ} 01 / 2007$, segundo o qual os condenados ao regime semiaberto, devem cumprir no mínimo 1/12 da pena para gozarem do benefícioe de trabalho externo.

No regime semiaberto não há previsão de isolamento durante o repouso noturno, bem como não existe na Lei de Execuçôes Penais - qualquer dispositivo que exija o cumprimento de $1 / 12$ da pena para poder ter os benefícios do regime aplicado. Tal regime é caracterizado pelo trabalho no período diurno e recolhimento a estabelecimento adequado no período noturno.

O que vem ocorrendo com a aplicação da Portaria n. ${ }^{\circ} 1 / 2007$ - é uma violação aos direitos e garantias fundamentais conquistadas a pesados custos no Estado Democrático brasileiro. Não é possível que os apenados aguardem em regime prisional mais gravoso (fechado), por 1/12 até adquirirem o direito de poder exercer atividade laboral ou de estudo.

2 Apelação n. 70066120841 ( ${ }^{\circ}$ CNJ: 0297462-41.2015.8.21.7000) - 2015 - Crime. DESCLASSIFICAÇÃO PARA A CONTRAVENÇÃO DE IMPORTUNAÇÃO OFENSIVA AO PUDOR. IMPOSIÇÃO DE APLICAÇÃO DO PRINCÍPIO DA PROPORCIONALIDADE. INFRAÇÃO DE MENOR POTENCIAL OFENSIVO. COMPETÊNCIA DO JUIZADO ESPECIAL CRIMINAL. Não há falar em estupro, mas sim de contravenção penal de importunação ofensiva ao pudor se os atos praticados pelo réu não evidenciaram dolo de conjunção carnal ou de atentado violento ao pudor. Assim, considerando-se os atos praticados pelo réu, sob a perspectiva material, e seu ajuste à norma penal, de onde se tem a estreitíssima tipologia penal oferecida pela legislaçáo brasileira em termos de crimes sexuais, conclui-se que, sob os ditames do princípio da proporcionalidade e da vertente doutrinária majoritária da necessidade de consolidação de Direito Penal mínimo, é forçoso concluir, com base no princípio da proporcionalidade, que os fatos em tela melhor se ajustam à contravenção penal de importunação ofensiva ao pudor. Operada a desclassificação para a infração penal de menor potencial ofensivo, a competência para conciliar, julgar e executar é expressa pela Lei 9.099/1995, razão pela qual a sentença deve ser desconstituída, com a remessa dos autos ao Juizado Especial Criminal, conforme preceitua o art. 383, $\$ 1^{\circ}$, do Código de Processo Penal.

3 Segundo despacho datado de 18 de dezembro de 2014 - I - Cadastrada, provisoriamente, em execução a condenação, o REGIME inicial de cumprimento será o SEMIABERTO. Indefiro o pedido para trabalho externo, observando-se que o apenado ainda náo implementou o cumprimento de $1 / 12$ da pena em regime SEMIABERTO, nos termos da Portaria $n^{\circ} 01 / 2007$, náo podendo usufruir de benefícios externos. Salvo remiçấo, o cumprimento de 1/12 estará implementado em 14/07/2015. 
A aplicação da Portaria $n^{\circ}$ 1/2007 frustra os direitos subjetivos que foram conferidos pelo ordenamento positivo ao condenado, pois é corolário ser impossível que a execução da pena privativa de liberdade em regime semiaberto seja cumprida parcialmente no regime fechado, isto é, em presídios públicos, nos quais axiologicamente não existe conexão alguma com colônia agrícola, industrial ou similar, conforme dita a Lei.

A doutrina há muito vinha alertando os Tribunais Superiores da inaplicabilidade do artigo 37 da LEP, no que tange ao regime semiaberto, ou seja, a utilização de cumprimento de $1 / 6$ de pena descrita pelo artigo anteriormente citado só está ligada ao regime prisional fechado, no regime fechado após um sexto do cumprimento da pena, ele já pode pleitear a progressão para o regime semiaberto, outro sinal de que poderá estar apto a dar início ao trabalho externo. É cristalino doutrinariamente (BITENCOURT, 2014, p. 615) que o regime semiaberto deve iniciar com o direito ao trabalho diurno e recolhimento noturno.

O Superior Tribunal de Justiça passou a adotar o entendimento da desnecessidade do cumprimento de $1 / 6$ para a concessão do trabalho externo desde o ano de 2008, para quem cumpre pena em regime semiaberto, com o julgamento do HC 97.615/SP, atualmente são extremamente frutíferos dos posicionamentos nesse sentido, inclusive no Tribunal de Justiça do Rio Grande do Sul.

Não há que se discutir no presente caso qualquer discurso de fundamentação, pois esses já foram feitos pelo legislador, inclusive Habermas (2005), que deixa claro que se deve utilizar apenas discursos de aplicação nesse caso, pois onde se lê: trabalho no período diurno e descanso no período noturno significa, exatamente, trabalho no período diurno e descanso no período noturno, não há margens para interpretação.

Os descritos anteriores demonstram a total insegurança do sistema jurídico, pois juízes criam leis, não fundamentam suas decisões, e os membros do ministério público não fiscalizam a lei, usam de sua atribuição, de detentor da ação penal para denunciar levianamente os cidadáos que deveria proteger. 


\subsection{Apelação Cível Número 70005798004/2003 - $7^{a}$ Câmara Cível - TJRS e sua resposta correta}

Ao que se sustenta desde o início do texto, os processos paradoxais - ou seja, difíceis -, são de extrema importância para que a integridade do sistema jurídico possa ser mantida, principalmente, para possibilitar novas formas de aplicação jurídica, em que as normas por meio das regras não possibilitam a aplicação direta.

O Desembargador Brasil Santos, em seu voto no caso, afirma que não há uma lei em específico que possa ser aplicada, assim, não existindo base legal, o direito do meeiro estaria garantido, pois haveria uma lacuna.

Nesse sentido é importante distinguir entre lacuna na lei e lacuna no direito, para Kelsen (STRECK, 1999, p. 83), quando se fala em lacunas no Direito, não é porque uma decisão seja logicamente impossível ante a falta de disposições aplicáveis, e sim, simplesmente, porque a decisão logicamente possível aparece ao órgão aplicador como inoportuna ou injusta. Onde se fala em lacuna há somente uma divergência do Direito positivo e do Direito considerado mais justo. Já a lacuna da lei ou técnica, é considerada quando o legislador omite na norma algo que deveria ter posto para que ela fosse aplicada tecnicamente. Exemplo: uma assembléia, para estar em exercício, tem se ser convocada pelo seu presidente; mas, ao mesmo tempo, determina que ela deve eleger o seu presidente (KELSEN, 2000, p. 273).

No caso concreto poderia ser mencionado que existe uma lacuna no direito, por não haver previsão legal de norma jurídica aplicável, porém, Kelsen (2000, p. 273) refuta essa ideia, pois mesmo quando o direito náo diz nada, ele está dizendo algo. Assim, devemos entender que se o legislador não criou a lei, não foi por esquecimento, mas porque não quis criar, ou seja, uma ordem jurídica negativa.

Sendo a norma um ato de vontade que regula a decisão humana, seria impossível prever todas as decisóes humanas em concreto. Assim, Kelsen apoia-se na decisão judicial que seria a continuação do direito, não o começo, pois o direito sempre estaria em processo de criação. Kelsen supera o positivismo exegético, mas abandona o principal problema do direito: a interpretação no nível de aplicação. Assim, ele ultrapassa a letra da lei, porém não responde como o julgador deve in- 
terpretar e aplicar a norma. O Desembargador não consegue ultrapassar a norma, muito menos fundamentar sua decisão em um nível de aplicação, sua decisão está incorreta positiva e interpretativamente.

Já a Desembargadora Berenice Dias, juntamente com seu colega Teixeira Giorgir, vão além da norma. Utilizam-se de parte do ordenamento jurídico, como a lei de introdução ao código civil, artigo $4^{\circ}$, e principalmente de seus próprios sensos de justiça, para que o meeiro infiel não receba a meação advinda de sua torpeza. Não há, porém, qualquer embasamento legal para sua aplicação, ao contrário, um grave perigo surge da utilização da consciência em prol da justiça, pois quem irá nos proteger da boa vontade dos bons?

As teses psicanalíticas (LAPLANCHE, 2001, p. 93), comprovam que a consciência só pode nos oferecer um processo lacunar dos processos psíquicos, pois somos incapazes de observar a maioria dos fatos ocorridos para utilizar a consciência precisaríamos de uma teoria que determine sua função e lugar, o que não existe no momento.

A resposta para a Apelação n. ${ }^{\circ} 70005798004 / 2003$, deveria passar por uma construção hermenêutica séria, que se preocupe com a integridade do ordenamento, bem como eleve o grau de constrangimento epistemológico pelo qual os julgadores devem passar, para que não se diga qualquer coisa sobre qualquer coisa.

\subsection{Etapas da Interpretação para uma Resposta Correta}

Interpretar não é opinar sobre o enunciado de um texto normativo, ao contrário, a interpretação é dar sentido ao texto, é desnudar o que está intrínseco na norma. A primeira etapa da interpretação é a pré-interpretação. Segundo Streck, "toda decisão deve se fundar em um compromisso (pré-compreendido). Esse compromisso passa pela reconstrução da história institucional do direito" (2015, p. 114). Assim, nenhuma interpretação sai de um grau zero de sentido, não existe tábua rasa, todo julgador deve buscar na história judicial a fundamentação para o seu caso, assim, manterá a integridade do sistema, estruturando sua interpretaçáo no sentido jurídico projetado pela comunidade política. 
A segunda fase da interpretação corresponde aos ajustes feitos ao caso concreto, às hipóteses judiciais que podem ser levantadas para o caso, as regras, princípios que podem/devem ser aplicados para solucionar o caso sob a luz constitucional;

Por fim, a terceira etapa é o olhar sobre o todo, quando se explica no caso concreto a melhor forma que possa manter a integridade jurídica, nesse sentido, gera-se e se mantém a integridade. Importantíssimo, mencionar que as etapas de interpretação são apenas metodológicas, pois na prática quando interpreto/aplico, não existe uma divisão material nessas características explicativas.

A construção de uma resposta correta para a Apelação n ${ }^{\circ} 70005798004 / 2003$, primeiro deve ser fundamentada de forma normativa, não apenas parafraseando artigos como os julgadores fizeram, mas fundamentando o caso em regras ou princípios. Como já mencionado, não existe uma regra específica para o caso, haveria uma lacuna nesse sentido, porém, utilizando a história institucional do direito, vislumbramos que, no código penal, existem fundamentos suficientes, que poderiam ajudar a evitar os benefícios do apelado com sua torpeza. Embora, sejam áreas distintas, penal e cível pertencem ao mesmo ordenamento e estão sob o manto constitucional.

Num segundo momento, a utilização do conceito panprocessual, poderia ter oferecido embasamento teórico ao caso em tela, uma decisão condenatória na esfera criminal, não poderia gerar benefícios na esfera civil, pois estaria rompendo com a adequação, integridade e harmonia entre os institutos jurídicos. Assim, a sentença condenatória deveria ter, por meio dos efeitos da condenação elencados no código penal, artigo 91, II, b, limitado os direitos em relação à meação advinda da área cível. Motivar a decisão judicial por falta de regras a serem aplicadas ou pela consciência pessoal cria um desconforto e um grave perigo ao sistema jurídico, pois, de fato, existem normas e princípios que poderiam ter sido utilizados no caso, com uma leitura superficial de Dworkin poderia se observar que não seria pertinente a um Estado constitucional e democrático, permitir que alguém pudesse auferir lucro com sua própria torpeza. 
Assim, a decisão poderia ter sido adequada à estrutura constitucional, mantendo a integridade e harmonia entre os sistemas penais e cíveis, repelindo o direito de meação do ex-esposo, pois todo direito adquirido pelo mesmo seria fruto de um assassinato, pelo qual foi condenado na forma qualificada.

\section{CONSIDERAÇÕES FINAIS}

Os passos que trilham a finalização de um artigo são feitos de forma sucessiva. Cada etapa é progressiva e busca o aumento do diálogo. Esse, portanto, não é o momento em que faremos a reflexão de todos os resultados já discutidos, mas é o espaço no qual será possível fazer apontamentos e reflexôes sobre as questôes já analisadas e aventadas.

$\mathrm{O}$ trajeto do artigo em momento algum mostra-se retilíneo, sua sinuosidade constante nos impóe um devotado ato reflexivo. A finalização de um diálogo torna-se um processo complexo, pois dialoga com as pretensôes já apontadas no passado, buscando um liame intrínseco com o futuro das propostas críticas, advindas de uma autorreflexão.

É sabido que as interpretaçôes são feitas pelos entes interpretativos e não meramente encontradas, só pela linguagem podemos reproduzir conhecimentos. Muitas vezes, os textos dizem muito mais do que seus autores gostariam de dizer, mas muito menos dos que os leitores gostariam que dissessem. O sistema jurídico vive no entremeio deste paradoxo, pois tem uma vasta linguagem que diz muito pouco para seus intérpretes, às vezes quase nada, enquanto seus leitores esperam sempre mais.

É certo que, com uma leitura séria dos paradoxos processuais, uma visão ampla do sistema jurídico é possível se chegar a uma decisão correta ou a mais correta para o caso. Nos dias atuais as decisóes não são interpretadas, mas opinadas pelos julgadores conforme suas consciências, sem uma fundamentação legal estruturada em teorias epistemológicas sérias. Importam-se conceitos e os carnavalizam ao bel-prazer do intérprete, sem qualquer constrangimento epistemológico. 
Assim, sustenta-se que uma decisão correta passa primeiramente pela utilização de uma teoria apta aos processos complexos gerados pela pós-modernidade. Segundo, que o intérprete tenha uma macro observação do sistema jurídico, social e político, para que possa decidir mantendo a integridade jurídica. Essa decisão necessariamente passa por uma (re)construção de toda história institucional do direito, pois nenhuma interpretação nasce de um ponto zero. Após analisar todas as possibilidades da utilização de regras e princípios, dos confrontos possíveis e de sua coerência constitucional, deve o julgador aplicar a norma que melhor corresponda à coerência constitucional do direito.

\section{REFERÊNCIAS}

BEVILÁQUA, Clovis. Código Civil dos Estados Unidos do Brasil. Rio de Janeiro: Editora Rio, 1975. Vol. IV.

BITENCOURT, Cezar Roberto. Tratado de Direito Penal. 20. ed. São Paulo: Saraiva, 2014.

CARNEIRO, Wálber Araújo. Hermenêutica jurídica heterorreflexiva: uma teoria dialógica do direito. Porto Alegre: Livraria do Advogado, 2011.

CLAM, Jean. Questôes fundamentais de uma teoria da sociedade: contingência, paradoxo, só-efetuação. São Leopoldo: Editora Unisinos, 2006.

DWORKIN, Ronald. O império do Direito. Tradução Jefferson Luiz Camargo. São Paulo: Ed. Martins Fontes, 1999.

. Levando os direitos a sério. São Paulo: Martins Fontes, 2014.

ÉSQUILO. Oréstia. 6. ed. Rio de Janeiro: Editora Jorge Zahar, 2003. Vol. II.

HABERMAS, Jürgen. Facticidad y validez: sobre el derecho y el Estado democrático de derecho em términos de teoría del discurso. 4. ed. Madrid: Trotta, 2005.

HEIDEGGER, Martin. Introdução à Filosofia. São Paulo: Martins Fontes, 2008.

KELSEN, Hans. Teoria Pura do Direito. Trad. João Batista Machado. São Paulo: Martins Fontes, 2000.

LAPLANCHE, Jean. Vocabulário de Psicanálise. 4. ed. São Paulo: Martins Fontes, 2001.

LYRA, Roberto. Comentários ao Código Penal. Rio de Janeiro: Revista Forense, 1942. Vol. II. 
PONTES DE MIRANDA, Francisco Cavalcanti. Tratado de Direito Privado. 3. ed. Rio de Janeiro: Editor Borsoi, 1973. Tomo LVIII.

SÓFOCLES. Antígone. Teatro Grego. São Paulo: W. M. Jackson INC, 1950. Vol. XXII. STRECK, Lenio Luiz. Hermenêutica Jurídica e $(m)$ crise. Porto Alegre: Livraria do Advogado, 1999.

. O que é isto - decido conforme minha consciência? 5. ed. Porto Alegre: Livraria do Advogado, 2015.

2016. Ânsia por condenar MPF - Disponível em: <http://www.conjur.com.

br/2016-mai-26/senso-incomum-ansia-condenar-mpf-usa-inversao-onus-prova-stf $>$. Acesso em: 7 jul. 2016.

TONET, Fernando. Reconfiguraçôes do Constitucionalismo: modelos constitucionais sistêmicos na pós-modernidade. 2. ed. Rio de Janeiro: Lumen Juris, 2016.

ZAFFARONI, Eugenio Raúl; PIERANGELI, José Henrique. Manual de Direito Penal Brasileiro. 11. ed. São Paulo: Revista dos Tribunais, 2015. 